\title{
FAKTOR-FAKTOR YANG BERPENGARUH TERHADAP MUSCULOSCELETAL DISORDERS PADA PERAWAT DI RUMAH SAKIT UMUM SARI MUTIARA MEDAN TAHUN 2017
}

\author{
Rizki Taufik ${ }^{1}$, Otniel Ketaren ${ }^{2}$, M. Sidan Umi Salmah ${ }^{2}$ \\ ${ }^{1}$ Program Studi Pasca Sarjana Kesehatan Masyarakat Universitas Sari Mutiara Indonesia \\ Email : rizkitaufikfisio@gmail.com \\ ${ }^{2}$ Dosen Program Studi Pasca Sarjana Kesehatan Masyarakat \\ Universitas Sari Mutiara Indonesia \\ Email: u.salmah73@yahoo.com
}

\begin{abstract}
Abstrak
Keluhan musculosceletal adalah keluhan pada bagian-bagian otot skeletal yang dirasakan oleh seorang dimulai dari keluhan sangat ringan sampai sangat sakit. Apabila otot menerima beban statis secara berulang dan dalam waktu yang lama, akan dapat menyebabkan keluhan berupa kerusakan pada sendi, ligamen dan tendon. Keluhan otot skeletal pada umumnya terjadi karena kontraksi otot yang berlebihan akibat pemberian beban kerja yang terlalu berat dengan durasi pembebanan yang panjang.

Tujuan penelitian ini untuk menganalisis faktor-faktor yang berpengaruh terhadap musculosceletal disorders pada perawat. Penelitian ini merupakan penelitian survey analitik dengan pendekatan cross-sectional. Penelitian dilakukan di Rumah Sakit Umum Sari Mutiara Medan di ruang ICU dan ruang IGD. Jumlah sampelnya adalah 38 orang. Analisa data dilakukan secara univariat, bivariat menggunakan uji chi-square, dan multivariate menggunakan uji regresi logistik berganda.

Berdasarkan hasil penelitian menunjukkan bahwa faktor-faktor yang berpengaruh terhadap musculoskeletal disorders pada perawat di rumah sakit umum sari mutiara medan yaitu jenis kelamin (p-value=0,002), masa kerja (p-value $=0,049)$, dan sikap kerja (p-value=0,000). Sedangkan variabel yang tidak berhubungan yaitu umur ((p-value=0,147). Sikap kerja merupakan variabel yang paling besar pengaruhnya terhadap musculosceletal disordersdengan ( $\mathrm{p}$-value= 0,003; $\mathrm{OR}=17,627 ; 95 \% \mathrm{CI}$ 2,68-115,957). Artinya sikap kerja memiliki peluang resiko 17,627 kali lebih besar terhadap keluhan musculosceletal disorders.

Diharapkan kepada perawat untuk terus memperhatikan pola gerakan saat melakukan aktifitas, agar tidak terjadi sikap kerja yang salah, sehingga dapat memicu munculnya musculosceletal disorders.
\end{abstract}

Kata Kunci : Faktor-faktor, musculosceletal disorders

\begin{abstract}
Musculosceletal complaints are a complaint on the skeletal muscle sections felt by a person starting from a very mild to very painful complaint. If the muscles receive static loads repeatedly and over a long period of time, they can cause complaints of joints, ligaments and tendons. Skeletal muscle complaints generally occur due to excessive muscle contraction due to heavy workload with long duration of loading.

The purpose of this study was to analyze the factors that influence musculosceletal disorders in nurses. This research is an analytic survey research with cross-sectional approach. The study was conducted at Sari Mutiara General Hospital Medan in ICU room and IGD room. The sample size is 38 people. Data analysis was done univariat, bivariate using chi-square, and multivariate test using multiple logistic regression test.

Based on the result of the research showed that the factors influencing musculoskeletal disorders at the nurses in public hospital of pearl extract are gender ( $p$-value $=0,002$ ), work period $(\mathrm{p}$-value $=0,049)$, and work attitude $(\mathrm{p}$-value $=0,000)$. While the unrelated variable is age $((\mathrm{p}$ value $=0.147$ ) .The attitude of work is the biggest variable of influence on musculoscelet disorders with $(\mathrm{p}$-value $=0,003 ; \mathrm{OR}=17,627 ; 95 \%$ CI 2,68-115,957) work has a 17.627 times greater risk of complaints of musculosceletal disorders.

It is expected that the nurse should continue to pay attention to the movement pattern when doing the activity, so that there is no wrong working attitude, so it can trigger the emergence of musculoscelet disorders.
\end{abstract}

Key words: Factors, musculosceletal disorders 


\section{PENDAHULUAN}

Pembangunan kesehatan pada hakekatnya adalah upaya yang dilaksanakann oleh semua komponen Bangsa Indonesia yang bertujuan untuk meningkatkan kesadaran, kemauan, dan kemampuan hidup sehat bagi setiap orang agar terwujud derajat kesehatan masyarakat yang setinggi tingginya, sebagai investasi bagi pembangunan sumber daya manusia yang produktif secara sosial dan ekonomis. Keberhasilan pembangunan kesehatan sangat ditentukan oleh kesinambungan antar upaya program dan sektor, serta kesinambungan dengan upaya-upaya yang telah dilaksanakan oleh periode sebelumnya (Kepmenkes, 2015).

Keselamatan dan Kesehatan Kerja Rumah Sakit yang selanjutnya disingkat K3RS adalah segala kegiatan untuk menjamin dan melindungi keselamatan dan kesehatan bagi sumber daya manusia rumah sakit, pasien, pendamping pasien, pengunjung, maupun lingkungan rumah sakit melalui upaya pencegahan kecelakan kerja dan penyakit akibat kerja di rumah sakit.

Keluhan muskuloskeletal adalah keluhan pada bagian-bagian otot skeletal yang dirasakan oleh seorang dimulai dari keluhan sangat ringan sampai sangat sakit. Apabila otot menerima beban statis secara berulang dan dalam waktu yang lama, akan dapat menyebabkan keluhan berupa kerusakan pada sendi, ligamen dan tendon. Keluhan hingga kerusakan inilah yang biasanya disitilahkan denga keluhan musculoskeletal disorders (MSDs) atau cedera pada sistem muskuloskeletal (Grandjean, 1993; Lemasaters, 1996 dalam Tarwaka).

Menurut data Kemenkes RI melalui Badan Pengembangan dan Pemberdayaan SDMK tahun 2016, total Sumber Daya Manusia Kesehatan di Rumah Sakit pada tahun 2015 sebanyak 493.856 orang yang terdiri dari 322.607 orang tenaga kesehatan $(65,32 \%)$ dan 171.249 orang tenaga penunjang kesehatan $(34,68 \%)$. Jumlah tenaga kesehatan terbanyak yaitu perawat sebanyak 147.264 orang $(45,65 \%)$ sedangkan jumlah tenaga kesehatan paling sedikit yaitu dokter gigi spessialis sebanyak 1.046 orang $(0,32 \%)$. Provinsi dengan jumlah tenaga kesehatan di rumah sakit terbanyak yaitu Jawa Tengah (44.885 orang), Jawa Timur (39.742 orang), dan Jawa Barat (39.008 orang).Provinsi dengan jumlah tenaga kesehatan di rumah sakit paling sedikit yaitu Kalimantan Utara (1.163 orang).

Rasio tenaga kesehatan terhadap jumlah penduduk merupakan indikator untuk mengukur ketersediaan tenaga kesehatan untuk mencapai target pembangunan kesehatan tertentu. Berdasarkan Keputusan Menteri Koordinator Bidang Kesejahteraan Rakyat Nomor 54 Tahun 2013 tentang Rencana Pengembangan Tenaga Kesehatan tahun 2011-2025, target rasio tenaga kesehatan terhadap jumlah penduduk pada tahun 2019 di antaranya rasio dokter umum 45 per 100.000 penduduk, rasio dokter gigi 13 per 100.000 penduduk, rasio perawat 180 per 100.000 penduduk, dan rasio bidan 120 per 100.000 penduduk.

Berdasarkan pengamatan peneliti, cara perawat mengangkat dan memindahkan pasien masih banyak yang kurang cocok dengan prosedur yang dianjurkan. Beberapa faktor yang mereka katakan adalah sudah tidak sempat, ada yang tidak tahu, dan karena faktor tugas yang emergency sehingga menyebabkan mereka harus bekerja cepat bahkan terkesan buru-buru.

Berdasarkan latar belakang yang dipaparkan di atas, maka peneliti tertarik untuk melakukan penelitian mengenai faktor-faktor yang berpengaruh terhadap muskuloskeletal disorder pada perawat di rumah sakit umum Sari Mutiara Medan.

\section{BAHAN DAN METODE}

Penelitian ini adalah observasi yang bersifat analitik dengan desain penelitian cross sectional yaitu peneliti mencari pengaruh antara variabel independen (faktor risiko) dengan variabel dependen (efek) dengan melakukan observasi sekaligus pada saat yang sama. Cross Sectional merupakan jenin penelitian observasional untuk membuktikan adanya pengaruh antara faktor resiko dan suatu efek (Myrnawati, 2016). Berdasarkan pengertian tersebut penelitian berguna untuk mengetahui faktor-faktor yang 
berpengaruh terhadapMusculoskeletal Disorders pada perawat di Rumah Sakit Sari Mutiara Medan Tahun 2017.

Penelitian dilakukan di Rumah Sakit Sari Mutiara Medan. Waktu Penelitian dilakukan pada bulan Juli 2017. Dalam penelitian ini populasinya adalah perawat IGD dan ICU yang ada di RSU Sari Mutiara Medan yang berjumlah 47 orang. Dalam penelitian ini seluruh populasi dijadikan sampel (total sampling). Sumber data didapat berdasarkan hasil kuesionar kepada responden.

Grup A.

Batang tubuh (trunk).
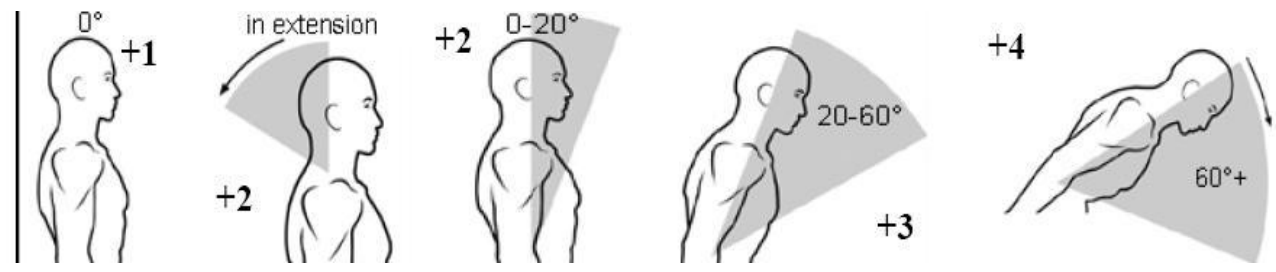

Gambar 3.1. Batang Tubuh (Tarwaka, 2015)

\begin{tabular}{|l|l|l|}
\hline Pergerakan & Skor & Skor Perubahan \\
\hline Posisi normal & 1 & berputar/bengkok/bungkuk \\
\cline { 1 - 2 }-20 & 2 & \\
\hline$<20$ atau 20-60 & 3 & \\
\hline$>60$ & 4 & \\
\hline
\end{tabular}
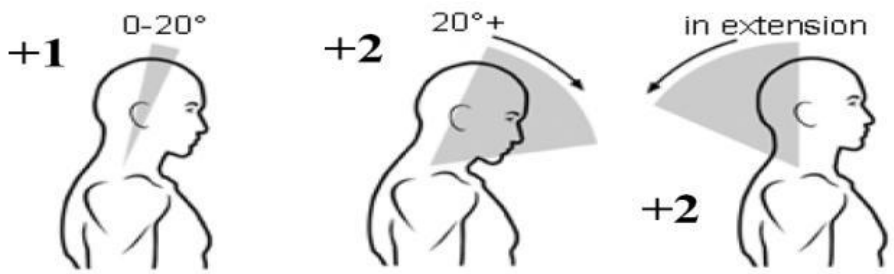

Gambar 3.2: Leher (Tarwaka, 2015)

\begin{tabular}{|l|l|l|}
\hline Pergerakan & Skor & Skor perubahan \\
\hline $0-20$ & 1 & $\begin{array}{l}+ \text { jika leher berputar / } \\
\text { bengkok. }\end{array}$ \\
\hline$>20$ atau ekstensi & 2 & \\
\hline
\end{tabular}
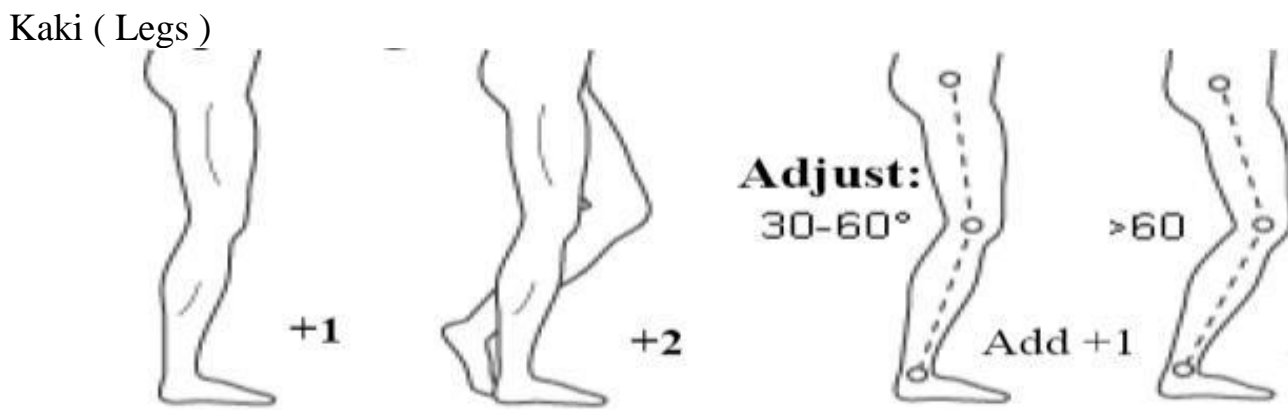

Gambar 3.3: Kaki (Tarwaka, 2015) 


\begin{tabular}{|l|l|l|}
\hline Pergerakan & Skor & Skor Perubahan \\
\hline $\begin{array}{l}\text { Posisi normal/seimbang } \\
\text { (berjalan/duduk) }\end{array}$ & 1 & $\begin{array}{l}+1 \text { jika lutut antara 30-60 } \\
+2 \text { jika lutut }>60\end{array}$ \\
\cline { 1 - 2 } $\begin{array}{l}\text { Bertumpu pada satu kaki } \\
\text { lurus. }\end{array}$ & 2 & \\
\hline
\end{tabular}

Untuk melengkapi skor pada grup A, maka selanjutnya adalah mengevaluasi posisi kaki. Skor pada kaki akan meningkat jika salah satu atau kedua lutut fleksi atau ditekuk. Kenaikan tersebut sampai dengan 2 , (+2) jika lutut menekuk > 60 derajat. Namun demikian, jika pekerja duduk, maka keadaan tersebut dianggap tidak menekuk dan karenanya tidak meningkatkan skor pada kaki (Tarwaka,

\section{Grup B}

Setelah selesai melakukan penilaian terhadap anggota tubuh pada grup A, maka selanjutnya harus menilai anggota tubuh bagian atas (lengan, lengan bawah dan pergelangan tangan) pada kedua sisi kiri dan kanan dan menilainya secara individu.

Lengan Atas (Upper Arm)
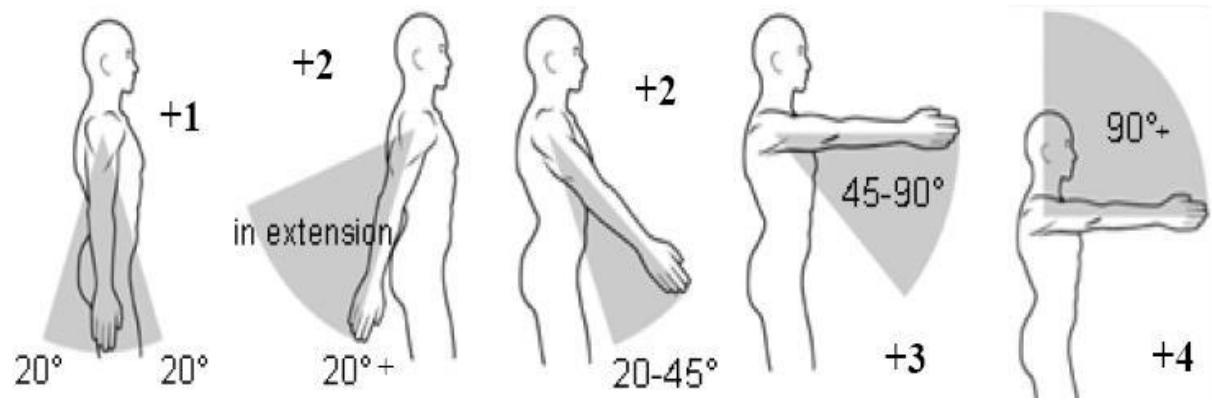

Gambar 3.4: Lengan Atas (Tarwaka, 2015)

\begin{tabular}{|l|c|l|}
\hline Pergerakan & Skor & Skor Perubahan \\
\hline 20 (ke depan dan belakang) & 1 & $\begin{array}{l}+1 \text { jika bahu naik } \\
+1 \text { jika lengan berputar/ } \\
\text { bengkok } \\
-1 \text { jika miring, menyangga } \\
\text { berat lengan }\end{array}$ \\
\hline$>20$ (ke belakang) atau 20-45 & 2 & 3 \\
\hline$>90$ & 4 & \\
\hline
\end{tabular}

Skor untuk lengan harus dimodifikasi, yaitu ditambah atau dikurangi jika bahu pekerja terangkat, jika lengan diputar atau diangkat menjauhi badan, atau dikurangi 1 jika lengan ditopang selama kerja.

Lengan Bawah
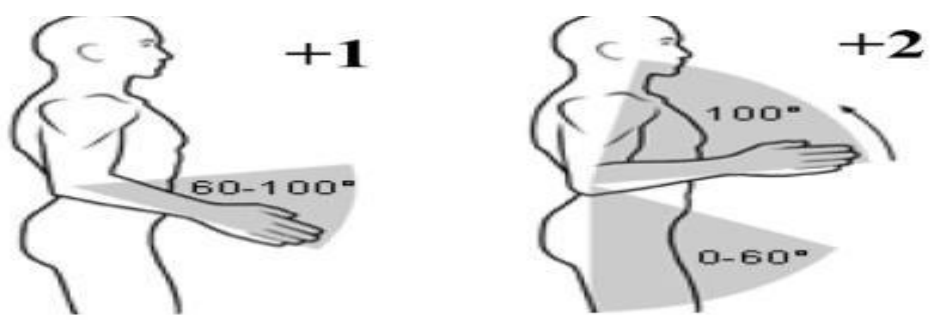

Gambar 3.5: Lengan Bawah (Tarwaka, 2015) 


\begin{tabular}{|l|c|}
\hline Pergerakan & Skor \\
\hline $60-100$ & 1 \\
\hline$<60$ atau $>100$ & 2 \\
\hline
\end{tabular}

Berikutnya yang harus dianalisa adalah lengan bawah. Skor postur untuk lengan bawah juga tergantung pada kisaran sudut yang terbentuk oleh lengan bawah selama melakukan pekerjaan. Pada gambar di atas menunjukkan perbedaan kisaran sudut yang mungkin terjadi. Setelah dilakukan penilaian terhadap sudut pada lengan bawah, maka skor postur pada lengan bawah langsung dapat dihitung.

Pergelangan Tangan (Wrist)
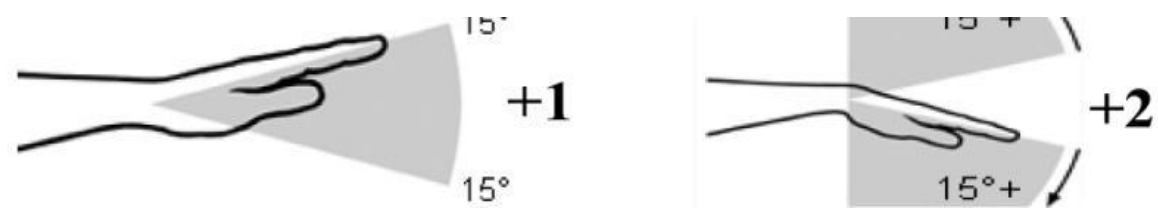

Gambar 3.6: Pergelangan Tangan (Tarwaka, 2015)

\begin{tabular}{|c|c|c|}
\hline & & \\
\hline Pergerakan & Skor & Skor Perubahan \\
\hline 0-15 (ke atas dan bawah) & 1 & \multirow{2}{*}{$\begin{array}{l}+1 \text { jika pergelangan tangan } \\
\text { putaran menjauhi sisi tengah }\end{array}$} \\
\hline$>15$ (ke atas dan bawah) & 2 & \\
\hline
\end{tabular}

Skor untuk pergelangan tangan ini atau deviasi baik ulnar maupun radial akan ditambah dengan 1 jika pergelangan (menekuk ke atas maupun ke bawah). tangan pada saat bekerja mengalami torsi

\begin{tabular}{|l|l|l|}
\hline \multicolumn{1}{|c|}{ Coupling } & \multicolumn{1}{|c|}{ Skor } & \multicolumn{1}{c|}{ Keterangan } \\
\hline Baik & 0 & Kekuatan pegangan baik. \\
\hline Sedang & 1 & $\begin{array}{l}\text { Pegangan bagus tetapi tidak } \\
\text { ideal atau kopling cocok } \\
\text { dengan bagian tubuh. }\end{array}$ \\
\hline Kurang Baik & 2 & $\begin{array}{l}\text { Pegangan tangan tidak sesuai } \\
\text { walaupun mungkin kaku, } \\
\text { pegangan tangan tidak } \\
\text { nyaman. }\end{array}$ \\
\hline Tidak dapat diterima & 3 & $\begin{array}{l}\text { Tidak ada pegangan atau } \\
\text { kopling tidak sesuai dengan } \\
\text { bagian tubuh. }\end{array}$ \\
\hline
\end{tabular}

\section{Skoring Group A dan B}

Skor individu yang diperoleh dari posisi badan, leher dan kaki (group A), akan memberikan skor pertama berdasarkan Tabel A.

\begin{tabular}{|c|c|c|c|c|c|c|c|c|c|c|c|c|}
\hline \multicolumn{13}{|c|}{ TABEL A } \\
\hline \multirow[t]{4}{*}{ Badan } & \multicolumn{12}{|c|}{ Leher } \\
\hline & \multicolumn{4}{|c|}{1} & \multicolumn{4}{|c|}{2} & \multicolumn{4}{|c|}{3} \\
\hline & \multicolumn{4}{|c|}{ Kaki } & \multicolumn{4}{|c|}{ Kaki } & \multicolumn{4}{|c|}{ Kaki } \\
\hline & 1 & 2 & 3 & 4 & 1 & 2 & 3 & 4 & 1 & 2 & 3 & 4 \\
\hline 1 & 1 & 2 & 3 & 4 & 1 & 2 & 3 & 4 & 3 & 3 & 5 & 6 \\
\hline 2 & 2 & 3 & 4 & 5 & 3 & 4 & 5 & 6 & 4 & 5 & 6 & 7 \\
\hline 3 & 2 & 4 & 5 & 6 & 4 & 5 & 6 & 7 & 5 & 6 & \begin{tabular}{|l} 
\\
\end{tabular} & 8 \\
\hline 4 & 3 & 5 & 6 & 7 & 5 & 6 & 7 & 8 & 6 & 7 & 8 & 9 \\
\hline 5 & 4 & 6 & 7 & 8 & 6 & 7 & 8 & 9 & 7 & 8 & 9 & 9 \\
\hline
\end{tabular}


Selanjutnya skor awal untuk grup B berasal dari skor posisi lengan, lengan bawah dan pergelangan tangan berdasarkan tabel $\mathrm{B}$ berikut:

\begin{tabular}{|c|c|c|c|c|c|c|}
\hline \multicolumn{7}{|c|}{ TABEL B } \\
\hline \multirow[t]{4}{*}{ Lengan } & \multicolumn{6}{|c|}{ Lengan Bawah } \\
\hline & \multicolumn{3}{|c|}{1} & \multicolumn{3}{|c|}{2} \\
\hline & \multicolumn{3}{|c|}{ Pergelangan Tangan } & \multicolumn{3}{|c|}{ Pergelangan Tangan } \\
\hline & 1 & 2 & 3 & 1 & 2 & 3 \\
\hline 1 & 1 & 2 & 2 & 1 & 2 & 3 \\
\hline 2 & 1 & 2 & 3 & 2 & 3 & 4 \\
\hline 3 & 3 & 4 & 5 & 4 & 5 & 5 \\
\hline 4 & 4 & 5 & 5 & 5 & 6 & 7 \\
\hline 5 & 6 & 7 & 8 & 7 & 8 & 8 \\
\hline
\end{tabular}

\section{Skoring untuk Beban atau Force}

Besar kecilnya skor untuk pembebanan dan force akan sangat tergantung dari berat ringannya beban yang dikerjakan oleh pekerja.

\begin{tabular}{|l|l|}
\hline Skor & Posisi \\
\hline+0 & Beban atau force $<5 \mathrm{~kg}$. \\
\hline+1 & Beban atau force antara $5-10 \mathrm{~kg}$. \\
\hline+2 & Beban atau force $>10 \mathrm{~kg}$ \\
\hline Skor & Posisi \\
\hline+3 & Pembebanan atau force secara tiba-tiba atau mendadak. \\
\hline
\end{tabular}

\section{Skoring untuk Jenis Pegangan}

Jenis pegangan akan dapat meningkatkan skor pada group B (lengan, lengan bawah, dan pergelangan tangan), kecuali dipertimbangkan bahwa jenis pegangan pada kontainer adalah baik.

\section{Analisis Univariat}

Dilakukan untuk melihat distribusi frekuensi masing-masing variabel.

\section{Analisis Bivariat}

Analisa bivariat dilakukan untuk melihat pengaruh antara faktor independen dengan faktor dependen.Variabel independen adalah Lama Kerja dengan variabel dependen yaitu Keluhan Muskulosekeletal Disorders.Analisis menggunakan uji T-test Independent dan Chi Square dengan $\alpha=0,05$.Namun apabila $\mathrm{T}$ - test Independent tidak bisa digunakan atau tidak terdistribusi normal pada variabel independen, maka digunakan uji mann witney dan untuk chi square jika tidak bisa digunakan atau sampel dibawah 20, nilai E-nya kurang dari 5 dan lebih di
$20 \%$ total selnya, maka uji yang digunakan adalah uji fisher exsact (Myrnawati, 2016).

\section{Analisis Multivariat}

Analisa multivariat dilakukan untuk mengetahui hubungan lebih erat dari satu variabel independen yaitu umur, jenis kelamin, waktu kerja, lama kerja, dan sikap kerja dengan satu variabel dependen yaitu musculosceletal disorders, secara bersamaan serta untuk mengetahui variabel dominan yang mempengaruhi. Uji statistik yang digunakan biasanya regresi berganda untuk mengetahui variabel independen mana yang paling erat hubungannya (Notoadmodjo, 2012).

\section{PEMBAHASAN \\ Analisis Bivariat \\ Umur dengan MSDs}

Tabel 4.6. Pengaruh Umur dengan keluhan Musculosceletal Disorders Pada Perawat ICU dan IGD RSU Sari Mutiara Medan Tahun 2017

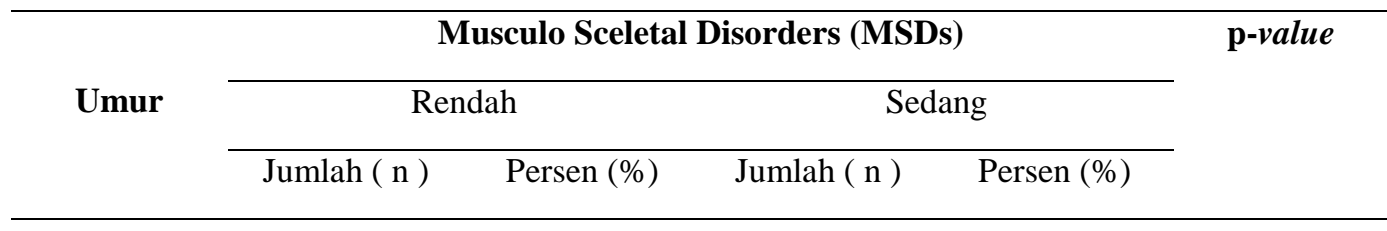




\begin{tabular}{cccccc}
\hline$\leq 30$ tahun & 13 & 34.2 & 13 & 34.2 & 0.147 \\
$>30$ tahun & 3 & 7.9 & 9 & 23.7 \\
\hline Total & 16 & 42.1 & 22 & 57.9 \\
\hline
\end{tabular}

Dari tabel 4.6 analisis bivariat umur dengan MSDs menunjukkan bahwa responden berumur $\leq 30$ tahun yang mengalami keluhan MSDs kategori rendah berjumlah 13 orang dan yang mengalami keluhan MSDs kategori sedang berjumlah 13 orang. Sedangkan untuk responden berumur > 30 tahun yang mengalami keluhan MSDs kategori rendah berjumlah 3 orang dan yang mengalami keluhan MSDs kategori sedang berjumlah 9 orang. Nilai $\mathrm{p}$-value menunjukkan $\mathrm{p}=0,147$ atau $\mathrm{p}$ $>0,05$ yang berarti tidak ada pengaruh umur dengan musculosceletal disorders.

Jenis kelamin dengan MSDs

Tabel 4.7. Pengaruh Jenis Kelamin dengan keluhan Musculosceletal Disorders Pada Perawat ICU dan IGD RSU Sari Mutiara Medan Tahun 2017

\begin{tabular}{|c|c|c|c|c|c|}
\hline \multirow{3}{*}{$\begin{array}{c}\text { Jenis } \\
\text { kelamin }\end{array}$} & \multicolumn{4}{|c|}{ Musculo Sceletal Disorders (MSDs) } & \multirow[t]{3}{*}{ p-value } \\
\hline & \multicolumn{2}{|c|}{ Rendah } & \multicolumn{2}{|c|}{ Sedang } & \\
\hline & Jumlah ( n ) & Persen $(\%)$ & Jumlah ( $n$ ) & Persen $(\%)$ & \\
\hline Pria & 10 & 26.3 & 3 & 7.9 & 0.002 \\
\hline Wanita & 6 & 15.8 & 19 & 50 & \\
\hline Total & 16 & 42.1 & 22 & $\begin{array}{l}57.9 \\
\end{array}$ & \\
\hline
\end{tabular}

Dari tabel 4.7. analisis bivariat jenis kelamin dengan MSDs menunjukkan bahwa responden pria yang mengalami keluhan MSDs kategori rendah berjumlah 10 orang dan yang mengalami keluhan MSDs kategori sedang berjumlah 6 orang. Sedangkan untuk responden wanita yang mengalami keluhan MSDs kategori rendah berjumlah 6 orang dan yang mengalami keluhan MSDs kategori sedang berjumlah 19 orang. Nilai p-value menunjukan $\mathrm{p}=0,002$ atau $\mathrm{p}<0,05$ yang berarti ada pengaruh jenis kelamin dengan keluhan musculosceletal disorders.

\section{Masa Kerja dengan MSDs}

Tabel 4.8. Pengaruh Masa Kerja dengan keluhan Musculosceletal Disorders Pada Perawat ICU dan IGD RSU Sari Mutiara Medan Tahun 2017

\begin{tabular}{|c|c|c|c|c|c|}
\hline \multirow{3}{*}{$\begin{array}{l}\text { Masa } \\
\text { Kerja }\end{array}$} & \multicolumn{4}{|c|}{ Musculo Sceletal Disorders (MSDs) } & \multirow[t]{3}{*}{ p-value } \\
\hline & \multicolumn{2}{|c|}{ Rendah } & \multicolumn{2}{|c|}{ Sedang } & \\
\hline & Jumlah ( n ) & Persen (\%) & Jumlah ( n ) & Persen $(\%)$ & \\
\hline$\leq 48$ bulan & 11 & 28.9 & 8 & 21.1 & 0.049 \\
\hline$>48$ bulan & 5 & 13.2 & 14 & 36.8 & \\
\hline Total & 16 & 42.1 & 22 & 57.9 & \\
\hline
\end{tabular}

Dari tabel 4.8. analisis bivariat masa kerja dengan MSDs menunjukkan bahwa responden dengan masa kerja $\leq 48$ bulan yang mengalami keluhan MSDs kategori rendah berjumlah 11 orang dan yang mengalami keluhan MSDs kategori sedang berjumlah 8 orang. Sedangkan untuk responden dengan masa kerja $>48$ bulan 
yang mengalami keluhan MSDs kategori rendah berjumlah 5 orang dan yang mengalami keluhan MSDs kategori sedang berjumlah 14 orang. Nilai p-value menunjukan $\mathrm{p}=0,049$ atau $\mathrm{p}<0,05$, yang berarti ada pengaruh masa kerja dengan keluhan musculosceletal disorders.

\section{Sikap Kerja dengan MSDs}

Tabel 4.9. Pengaruh Sikap Kerja dengan keluhan Musculosceletal Disorders Pada Perawat ICU dan IGD RSU Sari Mutiara Medan Tahun 2017

\begin{tabular}{cccccc}
\hline Sikap Kerja & \multicolumn{3}{c}{ Musculo Sceletal Disorders (MSDs) } & \multirow{2}{*}{ p-value } \\
\cline { 2 - 4 } & \multicolumn{3}{c}{ Rendah } & \multicolumn{3}{c}{ Sedang } & \\
\cline { 2 - 5 } & Jumlah ( $\mathrm{n})$ & Persen (\%) & Jumlah ( n ) & Persen (\%) & \\
\hline Sangat rendah & 5 & 13.2 & 1 & 2.6 & \\
Rendah & 10 & 26.3 & 1 & 2.6 & \\
Sedang & 1 & 2.6 & 16 & 42.1 \\
Tinggi & 0 & 0 & 4 & 10.6 \\
\hline Total & 16 & 42.1 & 22 & 57.9 \\
\hline
\end{tabular}

Dari tabel 4.9. analisis bivariat sikap kerja dengan MSDs menunjukkan bahwa responden dengan sikap kerja sangat rendah yang mengalami keluhan MSDs kategori rendah berjumlah 5 orang dan yang mengalami keluhan MSDs kategori sedang berjumlah 1 orang. Sedangkan untuk responden dengan sikap kerja rendah yang mengalami keluhan MSDs kategori rendah berjumlah 10 orang dan yang mengalami keluhan MSDs kategori sedang berjumlah 1 orang. Untuk responden dengan sikap kerja sedang yang mengalami keluhan MSDs kategori rendah berjumlah 1 orang dan yang yang mengalami keluhan MSDs kategori sedang berjumlah 16 orang. Untuk responden dengan sikap kerja tinggi yang mengalami keluhan MSDs kategori rendah tidak ada dan yang mengalami keluhan MSDs kategori sedang berjumlah 4 orang. Nilai p-value menunjukan $\mathrm{p}=0,000$ atau $\mathrm{p}<$ 0,05 yang berarti ada pengaruh sikap kerja terhadap keluhan musculosceletal disorders.

\section{Analisis Multivariat}

Tabel 4.10. Model Akhir Faktor-faktor yang berpengaruh dengan keluhan Musculosceletal Disorders Pada Perawat ICU dan IGD RSU Sari Mutiara Medan Tahun 2017

\begin{tabular}{ccccc}
\hline Variabel & B & Nilai-p & OR $(\operatorname{Exp}(\mathbf{B}))$ & 95\%CI \\
\hline Sikap Kerja & 2.869 & 0.003 & 17.627 & $2.68-115.957$ \\
Jenis Kelamin & 1.898 & 0.139 & 6.675 & $0.539-82.68$ \\
Masa Kerja & -0.329 & 0.785 & 0.720 & $0.068-7.669$ \\
Konstan & -9.376 & 0.003 & & \\
\hline
\end{tabular}

Berdasarkan tabel 4.10 dapat dilihat bahwa dari tiga variabel penelitian yang masuk kriteria uji multivariat didapatkan hasil uji regresi logistik. Sikap kerja dengan nilai $\mathrm{p}=0,003$ artinya sikap kerja berpengaruh terhadap musculosceletal disorders dengan $\mathrm{OR}=17,627$ yang artinya bahwa sikap kerja yang salah mempunyai peluang beresiko 
mengalami musculosceletal disorders 17,6 kali. Jenis kelamin dengan nilai $\mathrm{p}=0139$ dan $\mathrm{OR}=6.675$, yang berarti tidak ada pengaruh jenis kelamin terhadap musculosceletal disorders dengan resiko kejadian 6,75 kali. Dan masa kerja dengan nilai $\mathrm{p}=0785$ dan $\mathrm{OR}=0,720$, yang berarti tidak ada pengaruh masa kerja terhadap

\section{KESIMPULAN DAN SARAN \\ Kesimpulan}

Berdasarkan hasil penelitian mengenai faktor-faktor yang berpengaruh terhadap musculosceletal disorders di Rumah Sakit Umum Sari Mutiara Medan, maka didapatkan hasil kesimpulan sebagai berikut yaitu Tidak adanya pengaruh umur terhadap musculosceletal disorders pada perawat di RSU Sari Mutiara berdasarkan hasil ujian analisis bivariat yang didapatkan hasil nilai $\mathrm{p}=0,147$ atau nilai $\mathrm{p}$ $>0,05$ yang berarti Ho diterima dan Ha ditolak, ditemukan adanya pengaruh jenis kelamin terhadap musculosceletal disorders pada perawat di RSU Sari Mutiara berdasarkan hasil ujian analisis bivariat yang didapatkan hasil nilai $\mathrm{p}=0,002$ atau nilai $\mathrm{p}<0,05$ yang berarti Ho ditolak dan $\mathrm{Ha}$ diterima dan ditemukan adanya pengaruh masa kerja terhadap musculosceletal disorders pada perawat di RSU Sari Mutiara berdasarkan hasil ujian analisis bivariat yang didapatkan hasil nilai $\mathrm{p}=0,049$ atau nilai $\mathrm{p}<0,05$ yang berarti $\mathrm{Ho}$ ditolak dan Ha diterima.

\section{Saran}

\section{Bagi Perawat}

1) Dalam mengurangi munculnya kejadian musculosceletal disorder, sangat penting bagi perawat untuk memperhatikan peralatan yang digunakan seperti penggunaan alas kaki, pakaian, dan peralatan lain agar tidak mengganggu selama bekerja.

2) Perlu juga bagi perawat untuk sesekali melakukan peregangan otot sebelum bekerja dan setelah melakukan pekerjaan, agar otot tidak mengamali kelelahan.

3) Diharapkan perawat saling memantau dan mengingatkan rekannya jika diketahui menggunakan peralatan yang musculosceletal disorders dengan resiko kejadian 0,720 kali.

Jenis kelamin dengan nilai $\mathrm{p}=0.139$, berarti $\mathrm{p}>0,05$ artinya jenis kelamin tidak ada pengaruh terhadap musculosceletal disorders. Masa kerja dengan nilai $\mathrm{p}=0,785$, berarti $\mathrm{p}>0,05$ artinya masa kerja tidak ada pengaruh terhadap musculosceletal disorders.

beresiko memunculkan musculosceletal disorders ataupun saat melakukan gerakan yang salah.

\section{Bagi Rumah Sakit}

1) Asumsi peneliti bahwa nyeri haid atau menstruasi dapat menganggu konsentrasi perawat sehingga pekerjaan akan sulit dilakukan secara maksimal. Untuk itu pihak rumah sakit mungkin bisa mempertimbangkan memberikan cuti menstruasi kepada perawat wanita.

2) Di samping itu, pihak rumah sakit terus membekali perawat dengan pengetahuan untuk mengurangi resiko musculosceletal disorders. Bisa dengan menghadirkan ahli ergonomi ataupun mengajari mereka cara mengangkat yang benar dan peregangan yang benar.

\section{Bagi Peneliti Selanjutnya}

Kepada peneliti selanjutnya diharapkan agar mengembangkan penelitian ini lagi seperti dengan memperbanyak jumlah sampel dan memperbanyak variabel lainnya yang belum dibuat.

\section{DAFTAR PUSTAKA}

Akademi Fisioterapi Siti Hajar. (2011). Dokumentasi Persiapan Praktek Profesional Fisioterapi (DP3FT). Medan.

Akademi Fisioterapi Siti Hajar. (2007). Dokumentasi Persiapan Praktek Profesional Fisioterapi (DP3FT). Medan.

Budiman, F. (2015). Hubungan Posisi Kerja Angkat dengan Keluhan Musculosceletal Disorders pada Nelayan Tangkap di Muara Angke Pluit Jakarta Utara. Forum Ilmiah 
Volume 12 Nomor 1.Universitas Indonusa Esa Unggul. Jakarta

Fatmawati, A.Z. (2016). Hubungan Risiko Patient Handling Dengan Keluhan Muskuloskeletal Disorders pada Perawat Bagian IGD RSUD dr. Moewardi di Surakarta. Skripsi. FIK UMS. Surakarta

Helmi, Z.N. (2013). Gangguan Musculoskeletal. Jakarta. Salemba Medika

Kemenkes RI. (2016). Profil Kesehatan Indonesia 2015. Jakarta. Kemenkes RI.

Mindayani, S. (2012). Pengaruh Sikap Kerja Terhadap Keluhan Muskuloskeletal Pada Perajin Sulaiman Tangan di Nagari Koto Gadang Sumatra Barat.Tesis. FKM USU. Medan

Mutiah, A., Setyaningaih, Y., Jayanti, S. (2013). Analisis Tingkat Resiko Musculoskeletal Disorders (MSDs) dengan The Brief Survey dan Karakteristik Individu Terhadap Keluhan MSDs Pembuat Wajan di Desa Cepogo Boyolali. Jurnal Kesehatan Masyarakat Volume 2. Nomor 2. Fakultas Kesehatan Masyarakat. UNDIP.

Nala. (2001). Prinsip Pelatihan Fisik Olahraga. Denpasar. Program Pascasarjana Program Studi Fisiologi Olahraga. Program PascaSarjana UNUD.

Notoatmodjo, S. (2012). Metodologi Penelitian Kesehatan. Jakarta. PT Rineka Cipta.

Permenkes RI. (2016). Keselamatan dan Kesehatan Kerja Rumah Sakit. Diakses pada tanggal 1 April 2016.
Pratama, M.Y. (2012). Momentum Bulan K3 Nasional Tahun 2012. http://sumutpos.co/2012/01/11/mome ntum-bulan-k3-nasional-tahun-2012, diakses pada tanggal 20 Maret 2017.

Riyadana, W., Suharyanto, FX., Tana, L. (2008). Keluhan Nyeri Muskuloskeletal Pada Pekerja Industri di Kawasan Pulo Gading Jakarta. Jurnal Maj. Kedokteran Indonesia.Volume 58, Nomor 1.

Silaban, G. (2016). Keselamatan dan Kesehatan Kerja. Medan. CV. Prima Jaya

Susianingsih, A.F. (2014). Analisis Faktor Resiko Musculosceletal Disorders (MSDs) dengan Metode Quick Exposure Checklist (QEC) pada Pekerja Laundry. Artikel Ilmiah Hasil Penelitian Mahasiswa. Kesehatan Lingkungan dan Kesehatan Keselamatan Kerja. Fakultas Kesehatan Masyarakat. Universitas Jember.

Tarwaka. (2015). Ergonomi Industri: Dasar-dasar pengetahuan ergonomic dan aplikasi di tempat kerja. Surakarta. Harapan Press Solo

Tarwaka, Solichul HA. Bakri, Sudiajeng, L. (2004). Ergonomi untuk keselamatan, kesehatan kerja, dan produktivitas. Surakarta. Uniba Press.

Ulfah, N. dkk, (2014). Sikap Kerja dan Risiko Musculosceletal Disorders pada Pekerja Laundry. FKM Univ. Soedirman, Purwokerto. 